\title{
Physical Activity and Physical Activity Self-Efficacy of Adolescent Students: The Field-level Study in India and Fiji
}

\author{
Susmita Mandal ${ }^{1}$ and Subhas Chandra ${ }^{2}$ \\ ${ }^{1,2}$ School of Education, The University of the South Pacific, Fiji \\ Email: susmitammaiti@gmail.com
}

\begin{abstract}
Participation in physical activity (PA) builds self-efficacy required for adolescent development. This study investigates the extent of physical activity among the adolescent students and its influence on their physical activity self-efficacy (PSE) in two developing societies, India and Fiji. The PA level has been derived from responses on the time uses of 873 high school adolescent students studying at year 10 from 16 selected rural and urban schools. An index of PSE has been prepared using the sample responses and then following Cronbach's alpha of reliability test and method of principal component analysis (PCA). Finally, ANOVA and regression techniques have been applied to find statistical relationships. It is observed that almost $62 \%$ sample adolescent students are engaged in the lowest level of PA (0-1.4 hours per day) and 23\% spend even less than 30 minutes. The PA level and its self-efficacy of female adolescent students are substantially lower than those of boys. Further, the statistical results suggest that PA definitely improves PSE, but at a decreasing rate.
\end{abstract}

Keywords: Adolescent, physical activity, physical activity self-efficacy

\section{Introduction}

General and mental health problems during the adolescent period are increasing significantly in modern societies. People believe that physical activity (PA) deals only with their physical health problems and that it does not influence their mental health and well-being. Moreover, a major group of adolescents are more interested to engage in sedentary activities such as using computers, playing electronic games and watching TV [19]. As a result, PA declines dramatically during this period [7], [8] and [1]. This is also observed in more recent research as well [16] and [17]. The fall could be more pronouced in the developing societies where students seem to face much pressure due to fear of future unemployment. These issues lead to raise four initial questions: To what extent adolescent students are engaged on PA in developing societies, such as India and Fiji? Is there any variation among the levels of PA across gender in the presence of social constraints? Does the engagement in PA influence students' self-efficacy to regulate physical activity? If so, to what extent? Physical activity self-efficacy is very much essential for their sound development in life. This paper attempts to address these questions.

A growing body of research, though scanty, suggests that PA can prevent people suffering from various mental health syndromes by reducing their stress, anxiety and depression [[12], [13], [20] and [21]] along with physical health problems [7]. PA is immensely important during the adolescent period (from 12 years to the early 20s) since this period brings considerable physiological, psychological and social changes of human development. Adolescence is inherently a stage of "storm and stress" [10] and must be encouraged to build not only sound physical health but also their mental health.

PA is expected to be playing a favourable role for adolescents through developing their physical activity self-efficacy (henceforth, PSE) [20]. PSE refers to one's belief about one's capabilities to engage in PA [2], [3], [4] and [5]. This may regulate the adolescent students in such a way that could accelerate their self-confidence [5] and reduce the fluctuation of mood common during the adolescent period. The contemporary literature also discusses the relationship between PA and PSE. Stimpson's study [20] showed that respondents engaging in exercise frequently (action and maintenance stages) had high selfbelief to engage in PA even in a difficult condition. Similarly, the study of [18] indicated that environmental-change efficacy had the most significant influence on the children's engagement in PA.

In a typically developing society, particularly in India, schools and parents still encourage students to 
focus essentially on academic activities ignoring the other developmental issues in the adolescent period. Additionally, gender discrimination is predominant in the two traditional developing societies. Therefore, the current study aims to investigate the types as well as levels of PA among adolescent students across gender in these two countries. Such issues of adolescent in the context of gender disparity persisted in a typical developing society are still under-researched in the existing literature. In a very resent study, López Sánchez et al. [16] tried to estimate the level of habitual physical activity in children and adolescents from the Region of Murcia (Spain) using a questionnaire on Physician-based Assessment and Counselling for Exercise (PACE) among 1055 children and adolescents (532 males and 523 females), aged between 3 and 18 years. They found that the samples were not engaged in sufficient level of physical activity in comparison with the desired level, according to the recommendations of the World Health Organization. Moreover, boys are found more active than girls. In another study on Spain and India comparison, López Sánchez et al. [17] found almost similar results. Further, the study concluded that the level of physical activity is insufficient and decreases slightly with the age. However, both these studies considered sample of heterogeneous students with wide variation of their socio-psychological development.

The present study is similar to these two works, but a bit different way on certain aspects. We want to focus more on the adolescent than children to account for activity at the stage when an individual starts acting in response to their own consciousness. Activity of children is more driven by parents and schools. But, this may not be true for adolescent. Homogeneity is also preferred for deriving robust statistical analysis. In order to understand the strength of relationship, we attempted to prepare an index showing the level of physical activity (PA) and used it in the statistical manipulation. Moreover, this research attempts to investigate the influence of PA on PSE of adolescent students. The study assumes that a sufficient level of PSE can be achieved with a moderate level of PA and with the higher level, PA may not contribute to the PSE to the same extent. The existing literature did not examine such aspect of the relationship using statistical methods.

The study proposes to test the following hypotheses empirically.

(i) Moderate to high levels of PA are confined to limited adolescent students.

(ii) The level of PA among girl students would be substantially lower than that of boys.

(iii) The PA will improve PSE, but at a decreasing rate.

(iv) The PSE level of girls would also be lower than that of boys.

\section{Method}

\subsection{Participants}

Driven by limited scope and opportunity, the Indian field survey has been conducted during 2013-14 within urban, semi-urban and rural areas in the district of Midnapur which is located $70 \mathrm{~km}$ from Kolkata, West Bengal. Similarly, Suva (urban) and Rakiraki (rural) were chosen for sample survey in Fiji during the same period. In total, ten schools from India and six schools from Fiji were selected randomly at the region level. The Indian sample includes 435 adolescent students from $10^{\text {th }}$ standard (aged 14-17 years), of whom 245 are girls and the remaining 190, boys. Similarly, the Fijian sample size is 438 adolescent students, consisting of 252 girls and 186 boys.

Instrumentation: The research instruments used to measure the level of PA, PSE and other activities are presented below:

\subsection{Level of PA}

The study has utilized a self-recall and report measurement instrument followed by the Physical Activity Questionnaire for Adolescents (PAQ-A) developed by Kowalski, Crocker and Donen [14] with minor modifications. Two different approaches have been undertaken to help the students in recalling aspects of their PA. The first approach was to identify the list of activities, such as walking, jogging, running, cycling, swimming, dancing, baseball, softball, football, badminton, hockey, volleyball, basketball, physical exercise (PE), yoga, cricket, rugby and others. They reported on how much time they spent on each of these physical activities in the previous seven days. The second approach tries to 
account for the time spent for those activities by categorising different periods of a normal day in the last 7 days during the survey. PA captures such types of activities which range from moderate to vigorous intensities undertaken by the adolescent students. It excludes household activities, such as sweeping, mopping, washing, and gardening because those may not be conducive to deriving benefits on the psychological state(PSE).

\subsubsection{Indexation of PA}

Step 1: At first the study estimated the mean of the total times spent under first and second approaches as follows:

$$
\text { Average Level of PAin 7days (minute) }=\frac{\text { Totaltime spenton first approach }+ \text { totaltime spenton second approach }}{2}
$$

Step 2: To obtain the level of PA per minute, the average level of PA, derived in step 1, is divided by $7 * 24 * 60$.

$$
\text { Level of PA per minute }=\frac{\text { Averagelevel of PA in } 7 \text { days (minute) }}{7^{*} 24^{*} 60}
$$

Step 3: To determine the final index, the above level has been normalised by taking its difference from the minimum level and then, dividing by the difference between maximum and minimum PA per minute.

$$
\text { Level of } P A(\text { Index })=\frac{(\text { Level of PA per minute }- \text { minimumlevel })}{(\text { Maximumlevel }- \text { minimumlevel })}
$$

It is to be noted that the final index of the level of PA is unit free and varies within 0 and 1 . The entire level has been divided into five ranges to compare the level between the sample students and this is shown in Table 1 below:

Table 1. Ranges of the level of PA

\begin{tabular}{c|cc}
\hline Low & $0.00-0.20$ & $(0-84$ minutes per day $)$ \\
\hline Moderate & $0.21-0.40$ & $(84-168$ \\
\hline High & $0.41-0.60$ & $(2.8-4.2$ hours per day $)$ \\
\hline Very high & $0.61-0.80$ & $(4.2-5.6$ hours per day $)$ \\
\hline Extreme & $0.81-1.00$ & $(5.6-7$ hours per day $)$ \\
\hline
\end{tabular}

Note: Author's specification

The scale used here seems to be an arbitrary one and could be on the high side. Since an adolescent is usually more active than an adult when walking, cycling and engaging in the various games and sports included in the questionnaire, the scale, though it seems to be on the higher side for an adult, could reflect the right division for adolescent students for the purpose of the study.

\subsection{Level of PSE}

PSE is concerned with people's belief about themselves to regulate regular PA [6]. The study assumes that a PA efficacious outlook fosters people's intrinsic interest towards this activity and helps them to overcome various untoward situations for maintaining regular PA (Bandura, 1994). With this idea, the study has considered a PSE scale adopted by [6] in which 18 questions are designed to assess students' confidence for engaging in PA in different improper situations (e.g., when tired, when there are various problems etc.). The answers have been measured on a 10 -point scale, representing ' 0 ' as the lowest and ' 10 ' as the highest value (see Appendix A).

\subsection{Level of Other Activities}

The sample adolescent students were asked about their time spent on various activities such as learning, music/singing/drawing, video/computer games, indoor games and household tasks (e.g., mopping, sweeping, cooking ) during the previous 7 days. These activities have been added to the questionnaire to 
control their influences on the socio-psychological variable like PSE.

\subsection{Procedure}

After collecting the required data, the questions have been combined to construct a unique index to represent each variable. In order to do this for a psychological variable like PSE, Cronbach's alpha test [9] was applied to examine the reliability of all the instruments and then, an index has been constructed to combine them by using proper weights derived from the method of principal component analysis (PCA) [14], [15] and [22].

After indexation, analysis of variance (ANOVA) has been applied to investigate the significance of difference of PA across gender [13]. And finally, multiple regression analysis has been used to examine the extent of relationship between PA and PSE [13].

\section{Data Analysis}

From the first approach of the questionnaire on PA it is shown in the Table 2 that walking, bicycling and cricket are the most important and preferred physical activities among Indian sample students, whereas Fijian sample students are engaged more in walking, volleyball and rugby playing.

Secondly, in India boys and girls are engaged in PA in the ratio of 2:1. In Fiji, within the total PA the boys' share is 0.52 , which is marginally higher than that of girls (0.48).

Table 2. Distribution of PA by types across country and gender

\begin{tabular}{|c|c|c|c|c|c|c|c|c|c|c|}
\hline \multirow{3}{*}{$\begin{array}{l}\text { Types of } \\
\text { PA } \\
\end{array}$} & \multicolumn{5}{|l|}{ India } & \multicolumn{5}{|l|}{ Fiji } \\
\hline & \multicolumn{3}{|c|}{$\begin{array}{l}\text { Out of total activity } \\
\text { done by all students }\end{array}$} & \multirow{2}{*}{$\begin{array}{l}\text { Boys by } \\
\text { types out of } \\
\text { boys' total } \\
\text { activity }\end{array}$} & \multirow{2}{*}{$\begin{array}{l}\text { Girls by } \\
\text { types out of } \\
\text { girls' total } \\
\text { activity } \\
\end{array}$} & \multicolumn{3}{|c|}{$\begin{array}{l}\text { out of total activity } \\
\text { done by all students }\end{array}$} & \multirow{2}{*}{$\begin{array}{l}\text { Boys by } \\
\text { types out of } \\
\text { boys' total } \\
\text { activity }\end{array}$} & \multirow{2}{*}{\begin{tabular}{|l} 
Girls by \\
types out of \\
girls' total \\
activity \\
\end{tabular}} \\
\hline & $\begin{array}{l}\text { Types' } \\
\text { share }\end{array}$ & $\begin{array}{l}\text { Boys' } \\
\text { share }\end{array}$ & $\begin{array}{l}\text { Girls' } \\
\text { share }\end{array}$ & & & $\begin{array}{l}\text { Types' } \\
\text { share }\end{array}$ & $\begin{array}{l}\text { Boys' } \\
\text { share }\end{array}$ & $\begin{array}{l}\text { Girls' } \\
\text { share }\end{array}$ & & \\
\hline $\begin{array}{l}\text { Walking for } \\
\text { exercise }\end{array}$ & 0.16 & 0.10 & 0.07 & 0.15 & 0.20 & 0.34 & 0.16 & 0.18 & 0.30 & 0.39 \\
\hline Bicycling & 0.32 & 0.19 & 0.13 & 0.29 & 0.38 & 0.03 & 0.02 & 0.01 & 0.04 & 0.01 \\
\hline Swimming & 0.02 & 0.01 & 0.01 & 0.02 & 0.03 & 0.08 & 0.04 & 0.03 & 0.08 & 0.07 \\
\hline $\begin{array}{l}\text { Baseball, } \\
\text { softball }\end{array}$ & 0.01 & 0.01 & 0.00 & 0.01 & 0.01 & 0.00 & 0.00 & 0.00 & 0.00 & 0.00 \\
\hline Dance & 0.02 & 0.00 & 0.02 & 0.00 & 0.07 & 0.09 & 0.02 & 0.07 & 0.03 & 0.15 \\
\hline Football & 0.06 & 0.05 & 0.01 & 0.07 & 0.02 & 0.06 & 0.05 & 0.01 & 0.09 & 0.02 \\
\hline Badminton & 0.08 & 0.04 & 0.05 & 0.06 & 0.14 & 0.01 & 0.00 & 0.01 & 0.00 & 0.01 \\
\hline Hockey & 0.00 & 0.00 & 0.00 & 0.00 & 0.00 & 0.01 & 0.00 & 0.01 & 0.01 & 0.01 \\
\hline Volleyball & 0.02 & 0.02 & 0.00 & 0.03 & 0.00 & 0.14 & 0.07 & 0.07 & 0.12 & 0.15 \\
\hline Basketball & 0.01 & 0.00 & 0.00 & 0.00 & 0.01 & 0.04 & 0.02 & 0.02 & 0.03 & 0.04 \\
\hline $\begin{array}{l}\text { Physical } \\
\text { exercise, } \\
\text { yoga }\end{array}$ & 0.06 & 0.04 & 0.02 & 0.06 & 0.06 & 0.05 & 0.03 & 0.03 & 0.05 & 0.06 \\
\hline Cricket & 0.21 & 0.20 & 0.01 & 0.30 & 0.03 & 0.01 & 0.00 & 0.00 & 0.01 & 0.01 \\
\hline Rugby & 0.00 & 0.00 & 0.00 & 0.00 & 0.00 & 0.13 & 0.11 & 0.03 & 0.20 & 0.06 \\
\hline $\begin{array}{l}\text { Other } \\
\text { (specify) }\end{array}$ & 0.02 & 0.00 & 0.02 & 0.01 & 0.05 & 0.02 & 0.02 & 0.01 & 0.03 & 0.01 \\
\hline Total & 1.00 & 0.67 & 0.33 & 1.00 & 1.00 & 1.00 & 0.52 & 0.48 & 1.00 & 1.00 \\
\hline $\begin{array}{l}\text { Sample } \\
\text { number }\end{array}$ & 435 & 190 & 245 & 190 & 245 & 438 & 186 & 252 & 186 & 252 \\
\hline
\end{tabular}

Source: Author's calculation, Field Survey

According to the index of PA (discussed in the Instrumentation section), the highest proportion of 
students $(57.7 \%$ in India and $66.4 \%$ in Fiji respectively) belongs to the lowest range (Table 3). Then, gradually the share decreases with the higher levels of PA in both the countries. Across both countries together, the maximum share of students (62.1\%) lie within the lowest level. Moreover, approximately $23 \%$ of the sample adolescent students are engaged in PA even below 30 minutes per day in both countries. This shows engagement of adolescents on physical activities confines towards moderate to lower level and limited individuals.

Table 3. Level of PA by sample distribution

\begin{tabular}{l|l|r|r|r|r|r|r}
\hline Country & Range of PA & Boys & & Girls & & Total & \\
\hline \multirow{4}{*}{ India } & & No. & \multicolumn{1}{c|}{$\%$} & No. & \multicolumn{1}{c}{$\%$} & \multicolumn{1}{c}{ No. } & \multicolumn{1}{c}{$\%$} \\
\cline { 2 - 8 } & $0.0-0.20$ & 60 & 31.6 & 191 & 78.0 & 251 & 57.7 \\
\cline { 2 - 8 } & $0.21-0.40$ & 68 & 35.8 & 45 & 18.4 & 113 & 26.0 \\
\cline { 2 - 8 } & $0.41-0.60$ & 41 & 21.6 & 7 & 2.9 & 48 & 11.0 \\
\cline { 2 - 8 } & $0.61-0.80$ & 15 & 7.9 & 2 & 0.8 & 17 & 3.9 \\
\cline { 2 - 8 } & $0.81-1.00$ & 6 & 3.2 & 0 & 0.0 & 6 & 1.4 \\
\cline { 2 - 8 } & Overall & 190 & 100.0 & 245 & 100.0 & 435 & 100.0 \\
\hline \multirow{5}{*}{ Fiji } & $0.0-0.20$ & 105 & 56.5 & 186 & 73.8 & 291 & 66.4 \\
\cline { 2 - 8 } & $0.21-0.40$ & 42 & 22.6 & 44 & 17.5 & 86 & 19.6 \\
\cline { 2 - 8 } & $0.41-0.60$ & 20 & 10.8 & 19 & 7.5 & 39 & 8.9 \\
\cline { 2 - 8 } & $0.61-0.80$ & 14 & 7.5 & 2 & 0.8 & 16 & 3.7 \\
\cline { 2 - 8 } & $0.81-1.00$ & 5 & 2.7 & 1 & 0.4 & 6 & 1.4 \\
\cline { 2 - 8 } & Overall & 186 & 100.0 & 252 & 100.0 & 438 & 100.0 \\
\hline \multirow{5}{*}{ Total } & $0.0-0.20$ & 165 & 43.9 & 377 & 75.9 & 542 & 62.1 \\
\cline { 2 - 8 } & $0.21-0.40$ & 110 & 29.3 & 89 & 17.9 & 199 & 22.8 \\
\cline { 2 - 8 } & $0.41-0.60$ & 61 & 16.2 & 26 & 5.2 & 87 & 10.0 \\
\cline { 2 - 8 } & $0.61-0.80$ & 29 & 7.7 & 4 & 0.8 & 33 & 3.8 \\
\cline { 2 - 8 } & $0.81-1.00$ & 11 & 2.9 & 1 & 0.2 & 12 & 1.4 \\
\cline { 2 - 8 } & Overall & 376 & 100.0 & 497 & 100.0 & 873 & 100.0 \\
\hline
\end{tabular}

Source: Author's calculation, Field Survey.

In order to visualize the share of students against the level of PA, this has been plotted. All plots such as Kernel, normal, and t-distribution of the total sample students against the range of the PA suggest that the highest peaks lie almost within the lowest PA level (see Fig 1). This supports the previous discussion in both countries as well.

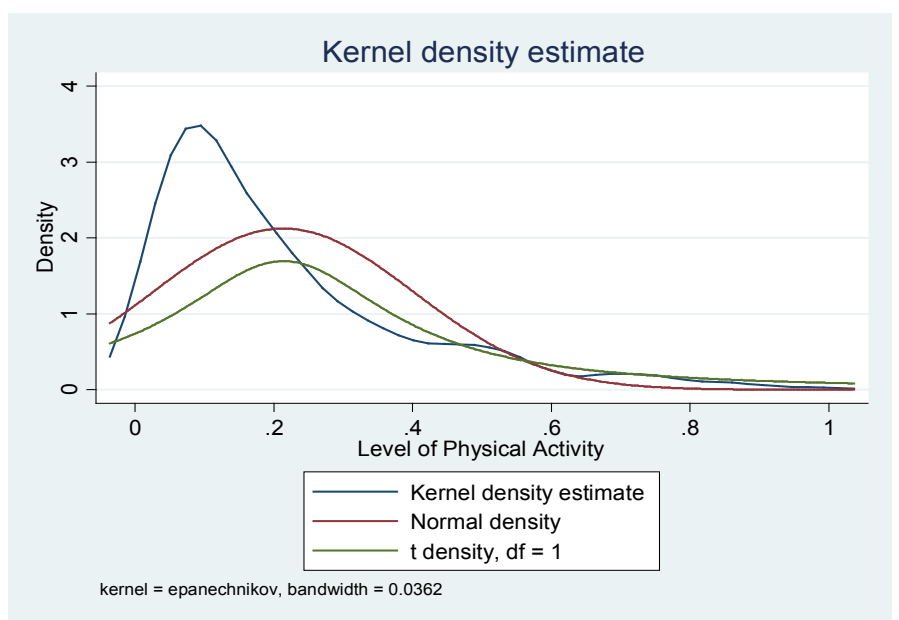

Figure 1. Distribution of the level of PA (Source: Author's calculation, Field Survey.) 


\subsection{Level of PA by Gender}

ANOVA has been undertaken between gender for the two countries together and each country separately. The derived F-statistics for the total sample (with $\mathrm{p}=0.00$ in Table 4 ) and each country separately (with $\mathrm{p}=0.00$ in Table 5) suggest that PA levels across gender are significantly different from each other. It is observed that the mean value of PA for girls has been consistently lower than that of boys in both countries separately as well as in total. For example, the average level of PA for girls combining two countries has been 0.15 which is almost of half of the boys.

Table 4. Summary statistics and ANOVA of the level of PA by gender combining two countries

\begin{tabular}{|c|c|c|c|c|c|c|}
\hline \multicolumn{7}{|c|}{ Summary statistics } \\
\hline Gender & \multicolumn{2}{|c|}{ Mean } & \multicolumn{2}{|c|}{ Std. Dev. } & \multicolumn{2}{|l|}{ Freq. } \\
\hline Girls & \multicolumn{2}{|c|}{0.150} & \multicolumn{2}{|r|}{0.135} & \multicolumn{2}{|c|}{497} \\
\hline Boys & \multicolumn{2}{|c|}{0.298} & \multicolumn{2}{|r|}{0.213} & \multicolumn{2}{|c|}{376} \\
\hline Total & \multicolumn{2}{|c|}{0.298} & \multicolumn{2}{|r|}{0.213} & \multicolumn{2}{|c|}{873} \\
\hline \multicolumn{7}{|c|}{ ANOVA } \\
\hline Source & \multicolumn{3}{|c|}{ SS } & MS & $\mathrm{F}$ & $\mathrm{P}$ \\
\hline Between groups & 1 & \multicolumn{2}{|c|}{4.687} & 4.687 & 156.59 & 0.00 \\
\hline Within groups & 871 & \multicolumn{2}{|c|}{26.073} & 0.030 & & \\
\hline Total & 872 & \multicolumn{2}{|c|}{30.760} & 0.035 & & \\
\hline
\end{tabular}

Note: Bartlett's test for equal variances $(\operatorname{chi} 2(1)=87.783 ; \mathrm{p}=0.00)$

Source: Author's calculation, Field Survey.

Table 5. Summary statistics and ANOVA of the level of PA by gender in two countries separately

\begin{tabular}{|c|c|c|c|c|c|c|}
\hline \multirow{10}{*}{ India } & \multicolumn{6}{|c|}{ Summary statistics } \\
\hline & Gender & Mean & Std. Dev. & \multicolumn{3}{|c|}{ Freq. } \\
\hline & Girls & 0.135 & 0.121 & \multicolumn{3}{|c|}{245} \\
\hline & Boys & 0.334 & 0.207 & \multicolumn{3}{|c|}{190} \\
\hline & Total & 0.222 & 0.191 & \multicolumn{3}{|c|}{435} \\
\hline & \multicolumn{6}{|c|}{ ANOVA } \\
\hline & Source & Df & SS & MS & $\mathrm{F}$ & $\mathrm{p}$ \\
\hline & Between groups & 1 & 4.256 & 4.256 & 158.25 & 0.00 \\
\hline & Within groups & 433 & 11.646 & 0.027 & & \\
\hline & Total & 434 & 15.902 & 0.037 & & \\
\hline \multirow{10}{*}{ Fiji } & \multicolumn{6}{|c|}{ Summary statistics } \\
\hline & Gender & Mean & Std. Dev. & \multicolumn{3}{|c|}{ Freq. } \\
\hline & Girls & 0.165 & 0.147 & \multicolumn{3}{|c|}{252} \\
\hline & Boys & 0.261 & 0.213 & \multicolumn{3}{|c|}{186} \\
\hline & Total & 0.206 & 0.184 & \multicolumn{3}{|c|}{438} \\
\hline & \multicolumn{6}{|c|}{ ANOVA } \\
\hline & Source & Df & SS & MS & $\mathrm{F}$ & $\mathrm{p}$ \\
\hline & Between groups & 1 & 0.990 & 0.990 & 31.24 & 0.00 \\
\hline & Within groups & 436 & 13.810 & 0.032 & & \\
\hline & Total & 437 & 14.800 & 0.034 & & \\
\hline
\end{tabular}

Note: Bartlett's test for equal variances $(\operatorname{chi} 2(1)=60.656, p=0.00$ for India; $\operatorname{chi} 2(1)=29.926, p=0.00)$ Source: Author's calculation, Field Survey. 


\subsection{PSE}

At first, the reliability test for all the questions used in the questionnaire related to PSE has been undertaken. It is observed that the signs of all questions are positive and inter-test correlations are high enough. The overall Cronbach's alpha combining all questions is 0.8126 and that is beyond the critical value of 0.7 (see Appendix A). So, it indicates that all the questions are sufficiently reliable to explain the variable.

Then, the principal component method has been applied to find the weights of each instrument to be used in the construction of the index and this provides separate and appropriate scores for all questions towards various uncorrelated dimensions. The most significant dimension (known as component 1) having the maximum eigenvalue 44.833 and $23.89 \%$ of the total variance (the largest variation) of the variables has been considered for weighting them. Note that all the coefficients for component 1 are statistically significant and the probability value of Chi-square suggests that the coefficients are significantly different from each other (see Appendix A). Hence, they can be used as weights to combine in linear form of index formation. The shared value of each coefficient is used with respect to the total value of all coefficients so that the sum of the weights will be exactly equal to one.

$$
\text { pse }_{\text {index } x c a}=\frac{\sum_{i=1}^{18} \omega_{i} p s e 0 i}{\sum_{i=1}^{18} \omega_{i}}
$$

where $\omega_{i}$ is the coefficient of $i$-th variable (question) found in component 1.

The density distribution of students across the range of PSE has been plotted (see Fig 2). As per Kernel and normal distributions of the sample students against PSE shown in the figure, the largest share of students falls within the average level of PSE, i.e., 5.

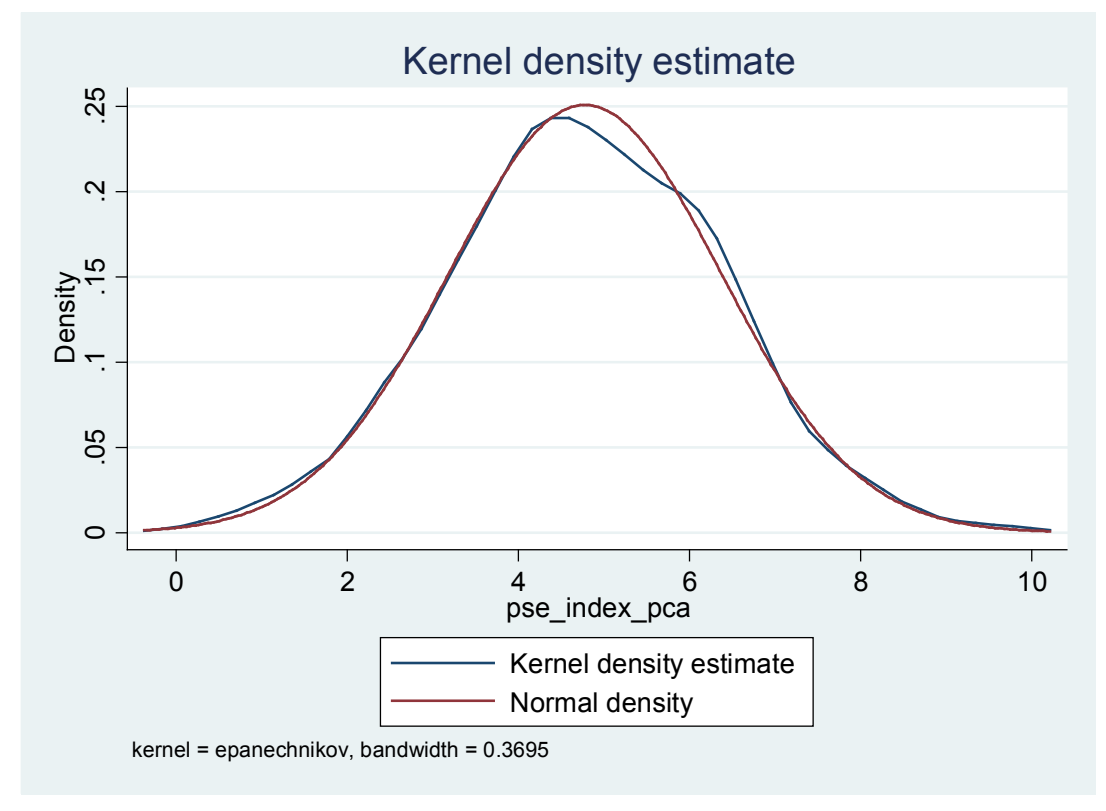

Figure 2. Kernel density distribution of PSE (Source: Author's calculation, Field Survey.)

\subsection{Effect of PA on PSE}

Now, the study wants to examine the relationship between PA and PSE. To do this, PSE was regressed on PA along with other sociocultural factors such as country, gender, learning activities, musical and cultural engagement, and household activities. The results of multiple regression have been presented in Table 6. The table shows that the regression coefficient of PA is 4.261 and the coefficient of square term of the variable is -3.682 . Both of them are statistically significant at the $5 \%$ level. Therefore, it suggests that PSE is increasing significantly with PA. But, it is seen that the rate decreases gradually. Again, it 
was found that boys' PSE is significantly greater than that of girls. The coefficient capturing the country effect for Fiji has not been found statistically significant.

Table 6. Regression results of PSE on the level of PA combining both countries

\begin{tabular}{l|l|r|l}
\hline Variable & Coefficient & Standard Error & P \\
\hline PA & $4.261^{* * *}$ & 0.834 & 0.00 \\
\hline$(\mathrm{PA})^{2}$ & $-3.682^{* * *}$ & 1.080 & 0.00 \\
\hline Fiji & 0.188 & 0.147 & 0.20 \\
\hline Boy & $0.560^{* * *}$ & 0.114 & 0.00 \\
\hline share of time spent on household works & $-1.230^{* *}$ & 0.571 & 0.03 \\
\hline share of time spent on learning activities & -0.382 & 0.589 & 0.52 \\
\hline share of time spent on music, singing and drawing & -0.107 & 0.648 & 0.87 \\
\hline Constant & $4.056^{* * *}$ & 0.257 & 0.00 \\
\hline
\end{tabular}

Note: Adjusted $\mathrm{R}^{2}=0.11, \mathrm{~F}(7,865)=16.34(\mathrm{p}=0.00)$

$* \mathrm{p}<0.10,{ }^{*} \mathrm{p}<0.05$ and $* * * \mathrm{p}<0.01$

Source: Author's calculation, Field Survey.

\section{$4 \quad$ Results and Discussion}

\subsection{Findings and Discussions}

The growing health hazards demand more participation in PA from the early stages of life. In virtually all societies people pay less attention to PA. The current study investigated the possible influence of PA on PSE of adolescent students in a typical developing society such as India and Fiji. The results from the data analysis and discussion can be summarized as follows:

1. Firstly, the sample students largely fall within the lowest level of PA with $23 \%$ even below 30 minutes per day. The activity mainly includes walking, bicycling and nationally popular sports. This is cricket in India and volleyball/rugby in Fiji. Students are engaged more in walking and bicycling largely because of limited transports and/or lack of its affordability, particularly for those who belong to lower income communities and live in remote villages.

2. Secondly, PA significantly raises the level of PSE, but at a decreasing rate. PSE rises with more PA, reaches the highest peak and then starts declining. This suggests that a sufficient level of PSE could be achieved with a moderate level of PA and it cannot be enhanced much beyond this level. This proves the third hypothesis. The result supports previously discussed Stimpson's study [20]. However, the present study is distinct by focusing on adolescent students and observing the extent of the relationship between PA and PSE.

3. Thirdly, boys participate in significantly more PA than girls. This could be related to the persistent discriminatory attitude towards the girl child in a traditional society and also could be due to lack of awareness of the importance of physical activity among girls. Moreover, boys have significantly better PSE than girls who have the same level of PA. This may be due to more exposure for boys in the traditional societies where gender inequality is deeply rooted.

The present study highlights the following contributions to the existing literature and understanding:

1. The study improves the attitude of people towards PA by showing its psychological benefits during the adolescent period.

2. The methodological framework applied for the study is quantitative. The quantitative answers on an ordinal scale of the questions designed for PSE are used for the indexation. This was executed by applying PCA, after undertaking the reliability test of all the instruments. Moreover, ANOVA and regression analysis have been applied to draw the relationships. Such methods are rarely applied in the existing literature in these areas.

3. The average levels of PA and its efficacy are significantly lower for girls than for boys. The gender dimension is an important issue in modern societies.

4. PA increases the level of PSE significantly, but at a decreasing rate. This is an important 
observation to find the critical value of PA, above which PSE will not be improved.

\subsection{Limitations of the Study}

1. The level of PA has been measured by the time devoted to specified PA. It has not been estimated using scientific caloric, muscular, skeletal or aerobic expenditures.

2. The study does not examine the critical level of PA above which PSE cannot be raised.

\subsection{Conclusion}

The present research study concludes that adolescent students must be encouraged to participate moderately in physical activities on a regular basis to protect themselves from growing health hazards. This activity also helps them to reduce their mood fluctuation and to be stronger in dealing with the conflicts in ever changing societies indirectly. Girl adolescent must be provided adequate opportunities and informed about advantages to be derived from regular physical activity.

\section{$5 \quad$ Implications for School Health}

The sample students were asked to respond on the extent to which their own PA is influenced by the school curriculum on a 5-point scale, indicating that higher the value lower is the importance and the results show an insignificant role of school influencing on the level of students' PA (not shown). Therefore, school authorities should encourage the students towards this activity sufficiently and adopt PA in their curriculum with due care and emphasis to raise students' efficacy.

Human Subjects Approval Statement. The study undertook clearances from all relevant authorities to conduct the survey.

Acknowledgement. *We acknowledge the support provided by the University of the South Pacific, Fiji for conducting the research and financial assistance. Special thank goes to Mrs. Asha Rao who motivated at various stages of the work. I also thank the editor and anonymous reviews of this journal for their comments and suggestions on the earlier draft. The usual disclaimer applies.

\section{References}

1. Allison, K., Adlaf, E., Dwye, J., Lysy, D., \& Irving, H. (2007). The decline in physical activity among adolescent students: a cross-national comparison. The Canadian Journal of Public Health; 98(2), 97-100.

2. Bandura, A. (1986). Social foundations of thought and action: A social cognitive theory. Prentice Hall: NJ.

3. Bandura, A. (1993). Perceived Self-efficacy in Cognitive Development and Functioning. Educational psychologist, $28(2), 117-148$.

4. Bandura, A. (1994). Self-efficacy. Encyclopedia of human behavior, 4(1 ), 71-81.

5. Bandura, A. (1997). Self-efficacy: The exercise of control: Macmillan. New York: Freeman.

6. National Center for Biotechnology Information, Available: http://www.ncbi.nlm.nih.gov

7. Bandura, A. (2006). Guide for Constructing Self-efficacy Scales. In F. Pajares \& T. Urdan (Eds.), Self-Efficacy Beliefs of Adolescents (pp. 307-337) . Charlotte, United States: Information Age Publishing.

8. CDC (1996a). Physical Activity and Health, Wangshingto, D.C., USA: Centers for Disease Control and Prevention, National Center for Chronic Disease Prevention and Health Promotion. Retrieved from http://www.cdc.gov/nccdphp/sgr/pdf/sgrfull.pdf

9. CDC (1996b). Guidelines for school health programs to promote lifelong healthy eating, Centers for Disease Control and Prevention, 45(RR-9) Atlanta, USA. Retrieved from http://www.cdc.gov/mmwr/pdf/rr/rr4509.pdf

10.Cortina, J. M. (1993). What is coefficient alpha? An examination of theory and applications. Journal of Applied Psychology, 78, 98-104.

11.Hall, G. S. (1904). Adolescence: Its psychology and its relation to physiology, anthropology, sociology, sex, crime, religion,and education. NJ: Prentice-Hall: Englewood Cliffs. 
12.Keller, G. (2013). Stats for Management \& Economics. (7th ed). Brooks:Cole.

13.Klein, M H., Grest, J H., Gunman, A S., Neimeyev, R A., Lesser, D P., Busell, N J., Smith, R E. (1985). A comparative outcome study of group psychotherapy vs exercise treatments for depression. International Journal of Mental Health, 13, 148-177.

14.Klein, S. \& Deffenbacher, J. (1977). Relaxation and exercise for hyperactive impulsive children. Perceptual and Motor Skills, 45, 1159-1162.

15.Lindman, C. \& Sellin, J. (2011). Measuring Human Development: The Use of Principal Component Analysis in Creating an Environmental Index. Uppsala University. Retreved from www.diva-portal.org/smash/get/ diva2:464378/FULLTEXT03

16.López Sánchez, G. F., Ahmed, D., Borrego Balsalobre, F. J., López Sánchez, L. \& Díaz Suárez, A. (2016a). Level of habitual physical activity in 8-9 years old schoolchildren from Spain and India. MHSalud: Revista en Ciencias del Movimiento Humano y Salud, 12(2), 1-10. http://dx.doi.org/10.15359/mhs.12-2.3

17.López Sánchez, G. F., González Víllora, S. \& Díaz Suárez, A. (2016b). Level of habitual physical activity in children and adolescents from the Region of Murcia (Spain). SpringerPlus, 5:386, 1-6. http://dx.doi.org/10.1186/s40064-016-2033-8

18.Ryan, G. J. \& Dzewaltowski, D. A. (2002). Comparing the Relationships between Different Types of SelfEfficacy and Physical Activity in Youth. Health Education \& AMP Behaviour , 29(4), 491-504.

19.Sibley, B. \& Etnier, J. (2003). The relationship between physical activity and cognition in Children: A metaanalysis. Pediatric Exercise Science, 15, 243-256.

20.Stimpson, T. S. (2000). Physical Activity Stages of Change, Self-efficacy, and Perceived Needs and Interests of Cooperative Extension Family and Consumer Sciences Agents and Clientele (Master thesis), Faculty of the Virginia Polytechnic Institute and State University, Blacksburg, VA.

21. Taras, H. (2005). Physical activity and student performance at school. Journal of School Health, 75(6), 214-218.

22.Vyas, S. \& Kumaranayake, L. (2006). Constructing socio-economic status indices: how to use principal components analysis. Health policy and planning, 9 October, 21 (6), 459-468. 


\section{Appendix}

Questionnaire and results of Cronbach's $\alpha$ test and PCA for PSE

\begin{tabular}{|c|c|c|}
\hline $\begin{array}{l}\text { Question: How certain you are that you can get yourself to perform } \\
\text { your physical activity routine regularly }(0-10 \text { point scale)? }\end{array}$ & alpha $^{a}$ & $\begin{array}{l}\text { PCA } \\
\text { Coefficient }^{b}\end{array}$ \\
\hline when you are feeling tired? & 0.804 & $0.183^{* * *}$ \\
\hline when you are feeling under pressure from work? & 0.802 & $0.223^{* * *}$ \\
\hline during bad weather? & 0.805 & $0.229 * * *$ \\
\hline after recovering from an injury that caused you to stop exercising? & 0.805 & $0.219^{* *}$ \\
\hline during or after experiencing personal problems? & 0.801 & $0.240^{* * *}$ \\
\hline when you are feeling depressed? & 0.803 & $0.208^{* * *}$ \\
\hline when you are feeling anxious? & 0.804 & $0.203^{* * *}$ \\
\hline after recovering from an illness that caused you to stop exercising? & 0.799 & $0.270 * * *$ \\
\hline when you feel physical discomfort when you exercise? & 0.800 & $0.247^{* * *}$ \\
\hline after a vacation? & 0.808 & $0.210^{* * *}$ \\
\hline when you have too much work to do at home? & 0.802 & $0.250 * * *$ \\
\hline when visitors are present? & 0.803 & $0.285^{* * *}$ \\
\hline when there are other interesting things to do? & 0.805 & $0.262^{* * *}$ \\
\hline if you don't reach your exercise goals? & 0.802 & $0.257^{* * *}$ \\
\hline without support from your family or friends? & 0.803 & $0.249^{* * *}$ \\
\hline during a vacation? & 0.811 & $0.209^{* * *}$ \\
\hline when you have other time commitments? & 0.807 & $0.210^{* * *}$ \\
\hline \multirow[t]{2}{*}{18.} & 0.804 & $0.260^{* * *}$ \\
\hline & $\begin{array}{c}\text { Overall alpha } \\
\quad=0.813\end{array}$ & \\
\hline
\end{tabular}

a shows the Cronbach's $\alpha$ coefficient for the test if the particular item in the row is eliminated.

${ }^{\mathrm{b}}$ derived from PCA. $[$ Rho $=0.239 ; \mathrm{SE}(\mathrm{Rho})=0.009$

LR test for independence $(\operatorname{chi} 2(153)=2753.99, \mathrm{p}=0.00)$

LR test for sphericity $(\operatorname{chi} 2(170)=2912.89, \mathrm{p}=0.00)$

$\mathrm{Chi}^{2}(17)$ test for equality of estimated coefficients $\left.=38.09, \mathrm{p}=0.002\right]$

${ }^{*} \mathrm{p}<0.10,{ }^{* *} \mathrm{p}<0.05$ and $* * * \mathrm{p}<0.01$

Source: Author's calculation, Field Survey. 